\title{
Load power and energy management system using proteus visual design software
}

\author{
Chitra Venugopal ${ }^{1}$, Thershen Govender ${ }^{2}$ \\ ${ }^{1}$ Department of Electrical Engineering and Renewable Energy, Oregon Institute of Technology, USA \\ ${ }^{2}$ School of Engineering, University of KwaZulu-Natal, South Africa
}

\begin{tabular}{l} 
Article Info \\
\hline Article history: \\
Received Apr 5, 2019 \\
Revised Mar 30, 2019 \\
Accepted Jan 20, 2020 \\
\hline
\end{tabular}

Keywords:

Arduino mega

Automation

Energy monitoring

Load analysis

Power management

Proteus visula designer suite

Single phase

Three phase load

\begin{abstract}
At present, there is a serious energy crisis around the globe which impacts greatly on the power grid. A smart and user friendly energy management system can control the energy consumption. In this paper, load power and energy management system is developed and simulated using Proteus Visual Design software. The load analysis and measurement techniques are developed for single phase and three phase loads and implemented using Arduino Mega 2560 board. User friendly controls are developed using the visual design feature of the software to control the energy consumption. The load power management system is simulated by measuring the power consumed by various residential loads such as lights, fans, air-conditioners, heaters. The industrial loads are simulated by squirrel cage induction motor. The load analysis summary is displayed on the Arduino 2.8 inch TFT display shield in a table format. The simulaion model is created for future hardware implementation and is tested under various practical input conditions. The Proteus Visual Design software is chosen in this resesarch due to its advantages such as professional PCB layout package, availability of nearly 800 microcontrollers in the library package etc. The developed model successfully measured the energy consumption of several loads and assist the user in controlling the energy usage through automation control techniques. The accuracy of the results shows that the technique and the model developed in this research can be used by engineers, students and hobbyists who are working with energy monitoring systems and smart home applications directly. This is an ongoing project where in the next stage, the hardware design of the simulation model will be implemented and tested in real time application.
\end{abstract}

Copyright $(0) 2020$ Institute of Advanced Engineering and Science. All rights reserved.

\section{Corresponding Author:}

Chitra Venugopal,

Department of Electrical Engineering and Renewable Energy,

27500 SW Parkway Ave, Wilsonville, OR, USA.

Email: Chitra.venugopal@ oit.edu

\section{INTRODUCTION}

In this day and age, the world faces an enormous challenge to meet the energy needs of a growing population and the energy resources are used sustainably. This issue of growing energy demand is a big challenge for many of the power companies supplying power to the grid. It is expected that in 2020, the energy usage will be increased by $70 \%$, however strategic energy management plans can help reduce the Greenhouse gas emissions by $57 \%$. Buildings account for approximately $50 \%$ of the greenhouse gas emissions [1]. According to the international energy report (2006), if energy efficiency is implemented in buildings then the world's energy need would drop to one-third by 2050, which will reduce the greenhouse gas emissions [2]. At present, the power companies are continuously challenged to ensure that their current energy supply can meet the present demand without implementing power cuts. The energy crisis in South 
Africa (where this research is conducted) has an adverse impact on both the residential and industrial sectors, which can pose a challenge to the economic growth of the country overall. The main root cause behind this energy crisis is due to the high energy consumption in the residential and industrial sectors respectively [3]. Due to the issue of growing energy demands and increasing tariffs (9.4\% increase in 2016/2017) [4], it is important that households and industries reduce their energy usage in order to save cost and maintain a balance between energy supply and demand.

There has been much advancement in the field of electrical metering, which was first invented in 1881 by Thomas Edison (1847-1931) [5]. The first electrical meter used the electrochemical process of copper deposition in order to determine electricity usage. However, this method and other analogue based methods were phased out in the 1900's after the advent of the micro-controller. The micro-controller's digital sampling based techniques offered a more accurate method of energy measurement over preceding analogue based methods. There have been developments in automated energy metering systems designed for domestic applications, which utilises an Arduino micro-controller system and Ethernet communication system [6]. The Arduino micro-controller system uses current and voltage sensing technology, which feed analogue voltage signals to the Arduino ADC's, using a level shifter method. This process reduces the accuracy of measurement. Another digital sampling techniques discuss various methods to read data from voltmeters, voltage dividers, shunt resistors for various measurements. The accuracy of this method is limited by the presence of harmonics in power measurements [7]. Many intelligent energy management systems are explored. One of the system using ZigBee technology presented in [8] discusses about a similar smart home arrangement discussed in this paper. The research was conducted and tested for temperature based equipments.

Schneider Electric offer building energy solutions which not only can increase the energy efficiency of the buildings but also decrease $30 \%$ of energy savings [9]. Smart energy metering technique is discussed in [10]. This uses android and GSM methods for monitoring net metering techniques. Other methods such as data collection from energy monitoring for various analysis is discussed in [11]. This method supports the data analysis methods rather than monitoring energy consumption. The smart energy metering techniques are discussed in [12-14] uses IoT techniques to transfer the data collected. The Hi-tech energy meter design [15] discusses the automatic load control. The data collection using GSM method is discussed in this paper. Though this paper addresses similar concept, the implementation method is much more complex to the method discussed in this paper. Artificial intelligence technique is used in smart metering technologies in [16]. This method also supports data collection, but the complexity limits its application for real time use.

There has been various research conducted on energy management systems using renewable energy sources as shown in [17-20]. Also, smart energy metering system has been discussed widely in [20-25]. These techniques are proven to work for larger system with or without wireless communication which adds complexity and consumes more power.

In this paper, a simple residential metering system for automated load power management system is discussed. The Proteus Visual Designer (PVD) tool is used to indicate the overall energy consumed and energy saving sysem is developed. This model uses load analysis measurement techniques to measure the energy consumption of several electrical loads. The main objective of the simulation model is to measure the energy consumption of residential and industrial model loads to control the energy usage of various operating loads on a daily basis. The power management aspect of the design is to automate the energy usuage system as per user defined set points.

The design of load analysis is divided into two simulation models, one for residential applications (single phase energy measurement) and one for industrial applications (three phase energy measurement). The proposed solution includes the following objectives:

a) The residential system needs to determine the real time energy usage for single phase ac loads using load analysis techniques and provide households with load energy usage readings of each respective load.

b) Allow the user to adjust set-points (i.e. light, temperature level etc.) using automation control techniques, in order to control energy usage efficiently.

c) The industrial system needs to determine the real time energy usage for three phase ac loads using load analysis techniques and provide users with load characteristics, more particularly power factor, which can be used to identify the efficiency of the machines at that time and to control its operation.

This paper is organized with 4 section. In Section 2, the design of single phase and three phase loads and power measurement tools in PVD is explained in detail. In Section 3, the energy measurment for various loads are displayed and the results are analyzed. Section 4, concludes the results and objectives achieved in this research. This is an ongoing project, in which the simulated design is implemented in hardware for real time application. The PVD software is used for the first time in load analysis technique and energy management system in this paper. The purpose of chosing PVD software compared to other softwares is due to it's accuracy in simulating a design closer to a real time application. The main advantage of this software is its library which contains all most all the components which are available in the market. There are more than 800 microcontroller 
model available in the library. Also, the availablity of professional PCB layout is vary much helpful to transfer the simulated design to hardware without much difficulty. The accuracy of the simulation model is also discussed in the conclusion. The simulation program is added in the appedix for the benefit of the readers.

\section{DESIGN OF LOAD POWER MEASUREMENT}

The residential load analysis and power management system was simulated using Proteus Visual Designer. There are three Arduino systems available on Visual Designer, of which the Arduino Mega 2560 best fits this application due to its larger memory (i.e. $256 \mathrm{~kb}$ ), more analogue to digital converter (ADC) pins (i.e. 16) and more digital input/output pins (i.e. 54). The Arduino 2560 can also be used for computing the power factor for the various operating loads. Proteus Visual Designer allows components and modules to be connected together by using terminal pins. A connection can be made by adding default terminal pins and giving them a matching name or by simply using the names which match the pins on the Arduino Mega 2560 system. The complete simulation diagram, with all the connected circuits and modules can be seen in Figure 1.

The simulation model of three phase load power management system is shown in Figure 2. Essentially it is important that the ratings of the voltage and current sensors are within the ratings of the operating load. For example, for a $12 \mathrm{~kW}$ squirrel cage Induction Motor load at $220 \mathrm{~V}$ ac balanced star connected and operating at a power factor of 0.95 , a $30 \mathrm{Amp}$ current sensor is used. A three phase $220 \mathrm{~V}$ ac squirrel cage induction motor (IM) is used as three phase loads for testing purpose. The individual load measurements of the simulation model is explained in the following sections.

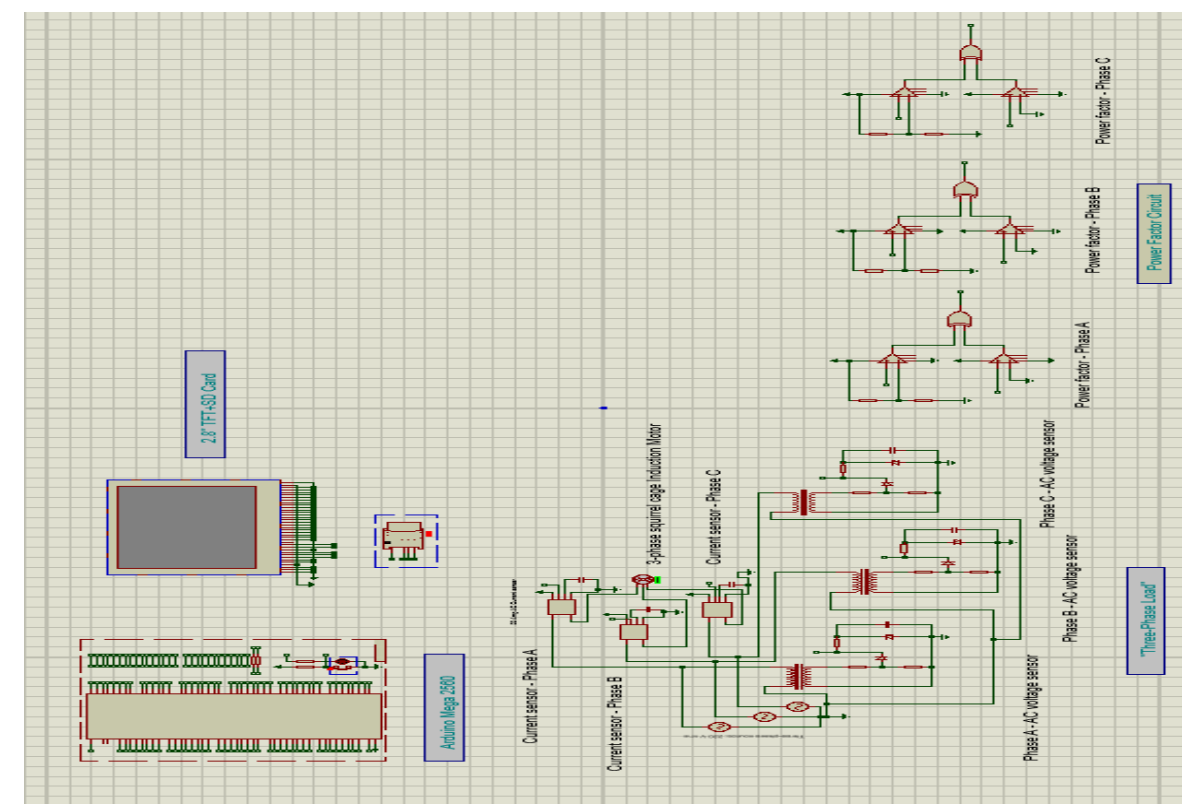

Figure 1. Simulation model of single phase load measurements

\subsection{Single phase and three phase load measurement and analysis}

The Proteus Visual Designer software for Arduino utilises a flowchart based programming scheme for designing and implementing micro-controller firmware for the Arduino system. Proteus Visual Designer has a large list of components available for simulation (i.e. current sensing modules, sensor probes for measurement etc.). The system is designed is explained in detail in the following sections.

\subsubsection{Single phase load measurement and analysis}

The general block diagram of the system designed for single phase residential load analysis and power management system is shown in Figure 3. The system is connected to the different domestic dc (i.e. led lighting) and ac loads (i.e. Fans, TV etc.) in a home, through voltage and current sensors. On start-up the system performs load analysis on each respective load, in a sequence starting from the first dc load to the last ac load. During load analysis the current sensors (which are series connected to the load), the voltage sensors (which are parallel connected to load) and power factor sensors (for ac loads only) send information 
regarding the load current, voltage and power factor parameters to the Arduino Mega 2560 board. The Arduino Mega system converts the measured analogue signals for voltage and current sensors into digital values, so that the measured parameters can be used to determine the real time power and energy values. The load analysis summary is displayed on the Arduino 2.8 inch TFT display shield in a table format.

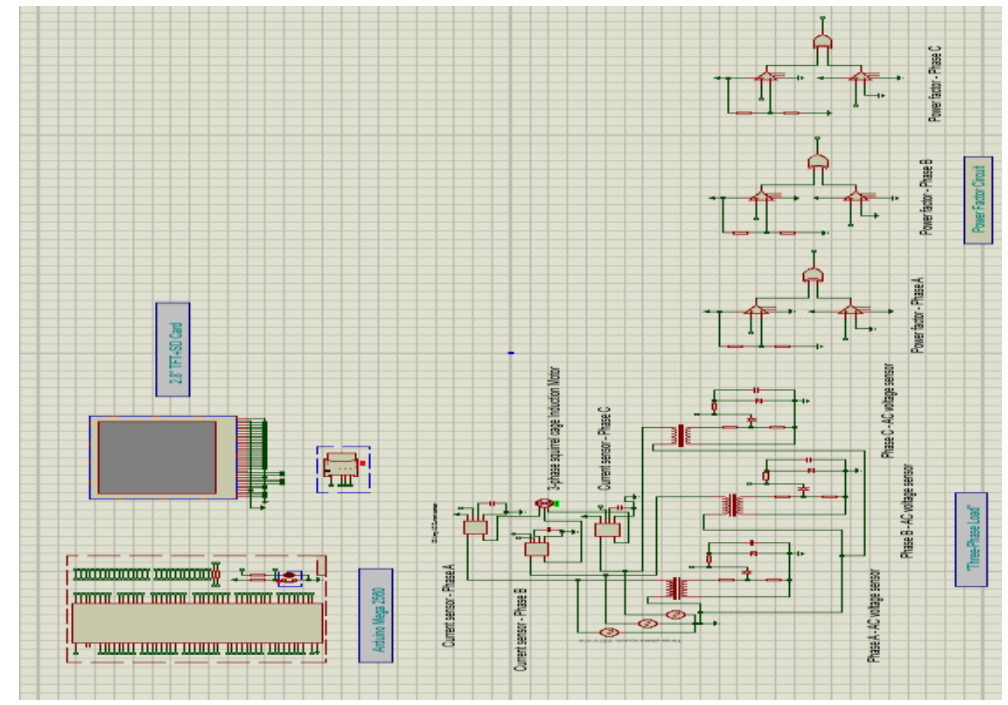

Figure 2. Full simulation schematic diagram three phase measurements

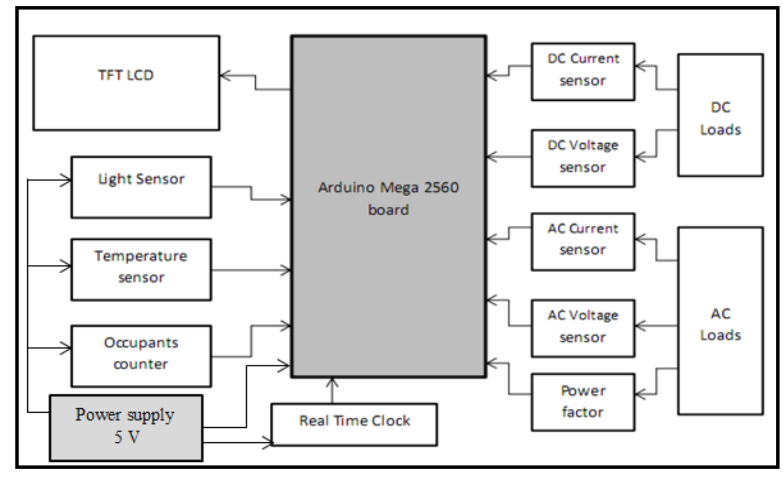

Figure 3. Functional block diagram of single-phase load measurement

The second aspect of this system is the power management aspect, which is achieved through using automation. Automation is achieved by using sensors and modules (i.e. light, temperature and time) in order to compare measured readings against the set points. The light sensor and temperature sensor provide the Arduino system with this information. The Arduino system applies ADC conversion techniques, in order to determine the measured values. The Real Time Clock (RTC) module sends the time and date to the Arduino system, which can allow the system to keep track of these parameters. The domestic DC and single phase AC power measurement and load analysis calculations used in this design are shown explained in the following sections.

\subsubsection{Three phase load measurement and analysis}

The functional block diagram for the three phase load analysis and power management system is shown in Figure 4. The system applies the same methodology of single phase load analysis to each respective phase of the three phase system which is delivering power to a single load (i.e. a three phase motor) or multiple loads through loading on each phase (i.e. buildings and street lighting using three phase system). The current and voltage sensors send information about the current and voltage magnitudes for each respective phase; furthermore, the current and voltage signals are fed to the power factor measurement circuit. This circuit applies the concepts of power factor measurement, as mentioned under the methodology 
section for power factor measurement and determines the phase difference between the voltage and current signals. This Arduino Mega system then measures this phase difference and determines the power factor. Once the power factor is determined, the power for each phase can be determined.

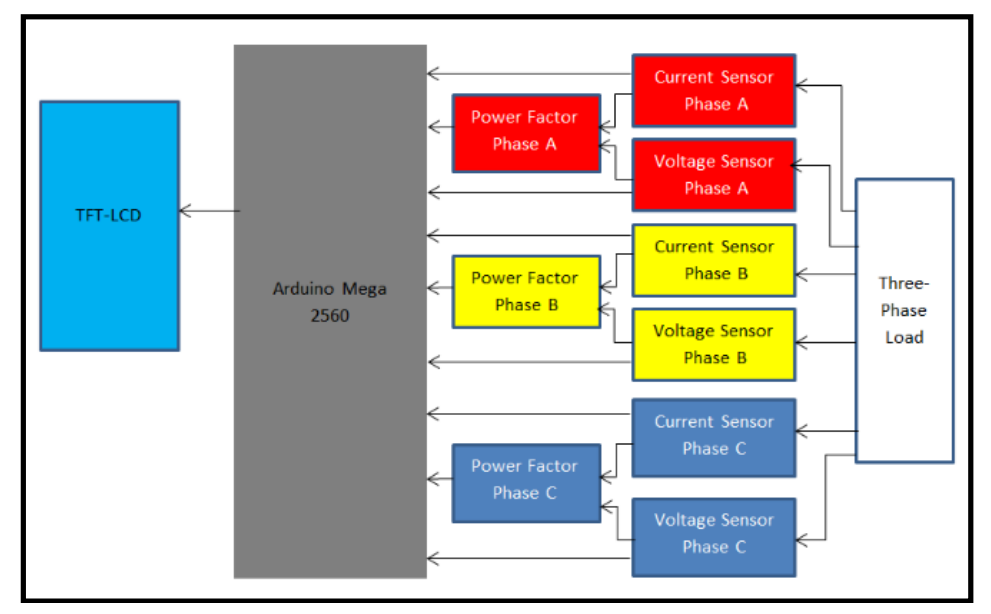

Figure 4. Functional block diagram for three-phase load measurement

\subsection{Current and voltage measurement in visual designer}

The simulation model of current sensor circuit is shown in Appendix. Visual Designer has an ACS712 Hall Effect current sensing module for various differenr ratings (i.e. 5 A, 10 A, 30 A). These sensors can be interfaced with the Arduino ADC pins in order to determine the digital signal of the current measurement. These sensors can be used to measure AC and DC currents during simulation. Voltage sensors can be built using the components readily available (i.e. Transformers, resistors, diodes etc.) on Visual Design, as Voltage sensing modules are not readily available. This voltage sensor can be interfaced to the Arduino ADC pins, in order to compute the voltage measurement for the load in operation.

\subsubsection{DC current measurement}

The dc current for the dc load will be measured using the Hall-effect ACS-712- 5 Amp current sensor. The sensor current algorithm is designed based on the datasheet. The sensor current is determined based on the output voltage of the sensor using the output voltage characteristic versus input sensor current from the datasheet shown in [10]. By reading the analogue voltage at the output of the current sensor, using the ADC of the Arduino Mega, the sensor output voltage (V) can be determined.

\subsubsection{AC current measurement}

The ac current is measured using the ACS-712 Hall effect current sensor, depending on the load being measured. In the simulation a $20 \mathrm{~A}$ range current sensor was selected, this current sensor is capable of measuring both forward and reverse current. The function of the output voltage versus sensor current can be obtained from the datasheet shown in [10]. This function returns positive and negative results, depending on the output voltage determined by the sensor on the adc. The sensor output voltage is determined by reading the analogue voltage (i.e. in terms of analogue count) of the current sensor and then performing an adc conversion. The peak current value is obtained by using a loop of 100 samples taken over a period of $0.02 \mathrm{sec}$. (Supply frequency is $50 \mathrm{~Hz}$ ). The rms value is obtained from the calculated peak value.

\subsubsection{DC voltage sensor}

The DC Voltage sensor circuit design used is shown in Appendix. For the dc loads, the voltage was determined using a high resistance divider in parallel with the dc load, to minimise the current losses. That the Arduino Mega's analogue to digital converter can be used to read the analogue input voltage.

\subsubsection{AC voltage sensor}

The design of the sub-circuit for the ac voltage sensor is shown in Appendix. The circuit measures the ac voltage, by using a rectification method. Since the microcontroller ADC on the Arduino Mega can read a maximum of $5 \mathrm{~V}$ (i.e. 1023), the measured signal needs to be within the range of $0-5 \mathrm{~V}$ dc. The $230 \mathrm{~V} \mathrm{rms}$ ac signal will be 
stepped down using a transformer (46:3 turn ratio) to $15 \mathrm{~V} \mathrm{rms,} \mathrm{this} \mathrm{signal} \mathrm{then} \mathrm{gets} \mathrm{reduced} \mathrm{using} \mathrm{a} \mathrm{high} \mathrm{resistance}$ resistor divider. The high resistance divider scales down the $15 \mathrm{~V} \mathrm{rms} \mathrm{ac} \mathrm{signal} \mathrm{according} \mathrm{to} \mathrm{the} \mathrm{resistance} \mathrm{divider}$ rule. The peak voltage of voltage sensor is $4.51 \mathrm{~V}$, which is within the adc voltage measurement range and this will prevent any damage to the adc. This sine signal then undergoes full bridge rectification, this results in the sine wave input becoming a dc signal. This is necessary to allow for the microcontroller to measure the analogue points during both cycles (positive and negative half cycles) so that the peak voltage can be determined.

\subsection{Light, temperature and occupancy sensor}

For an Automatic ON/OFF Nightlight, the light needs to be switched ON when the measured light level outdoors is less than the set point light level that user pre-sets. The light sensor (LDR) with set point is used in simulation block. The light and occupancy simulation circuit is shown in Appendix. The temperature sensor (LM-35) which measures the temperature of the external environment and allows the user to pre-set the set point temperature to control the fan and heater to save energy. The occupancy counter is built using a pair of infrared transmitter and receivers.

\section{RESULTS AND DISCUSSION}

The main objectives of this design are to design a low cost load analysis and power management system for residential and industrial applications, in order to measure real time energy usage for various operating loads for each respective application and to provide a user friendly system with a load summary of the electrical characteristics for each respective operating load. This would enable the user is able to take action in monitoring and cutting down on energy usage. To achieve this tasks, the design is divided into two sections, single phaase and three phase and the results are analyzed accordingly.

\subsection{Single phaes load power management analysis}

The specification of the loads that were tested in this simulation models is shown in Table 1. The screenshot of the TFT after one minute of simulation for the loads specified in Table 1 is shown in Figure 5. The sensor information is collected, and the energy consumed by connected loads, light and temperature adjustment control are calculated in the programming section of the software. The user input options are designed to view the sensor information, graphical data and the settings for set point parameters are shown in Figures 6, 7 and 8 respectively. The load analysis results are shown in Tables 2-6.

Table 1. Loads measured by single-phase meter on simulation

\begin{tabular}{lllll}
\hline \multicolumn{1}{c}{ Load name } & \multicolumn{1}{c}{ Load description } & Type & Resistance $(\Omega)$ & Quantity \\
\hline Lights & 12W, 12V led downlight (indoor) & DC & 12 & 3 \\
Outdoor Lights & 24W, 12V Outdoor led light & DC & 6 & 1 \\
Geyser & Geyser (3.1kW) & AC & 17 & 1 \\
Fan & Pedestal Fan $(300 \mathrm{~W})$ & AC & 176 & 1 \\
\hline
\end{tabular}

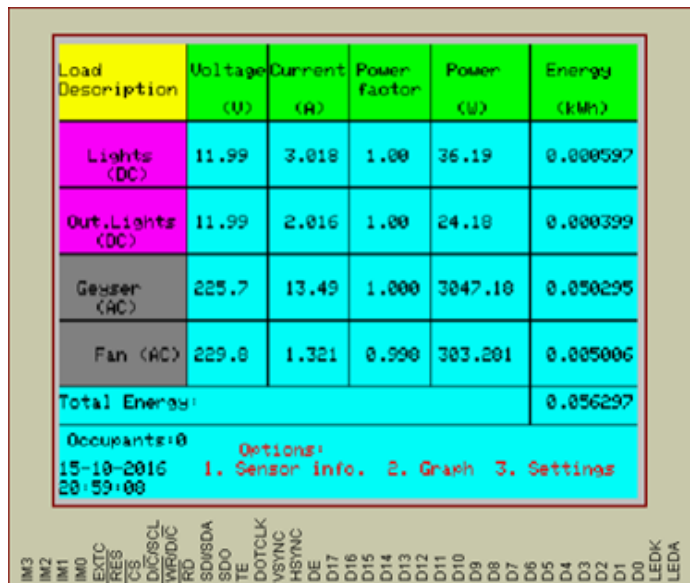

Figure 5. Screen display on TFT of simulation of real time system measurement for operating loads

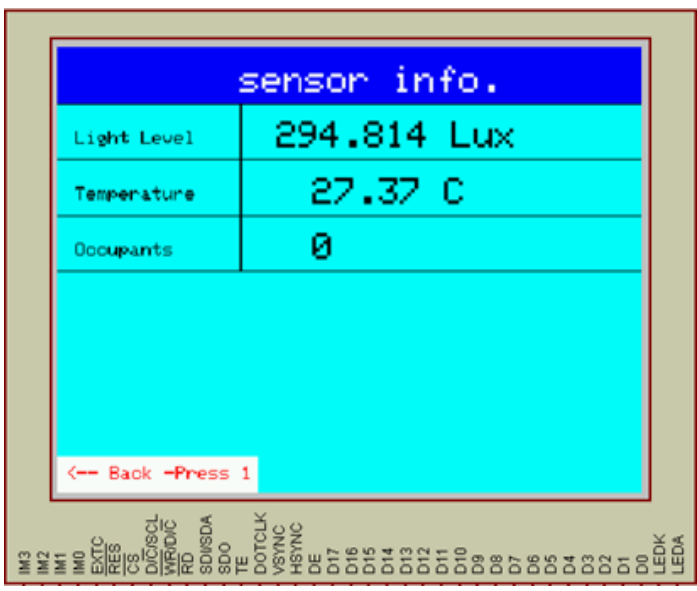

Figure 6. Sensor information displayed on TFT Screen 


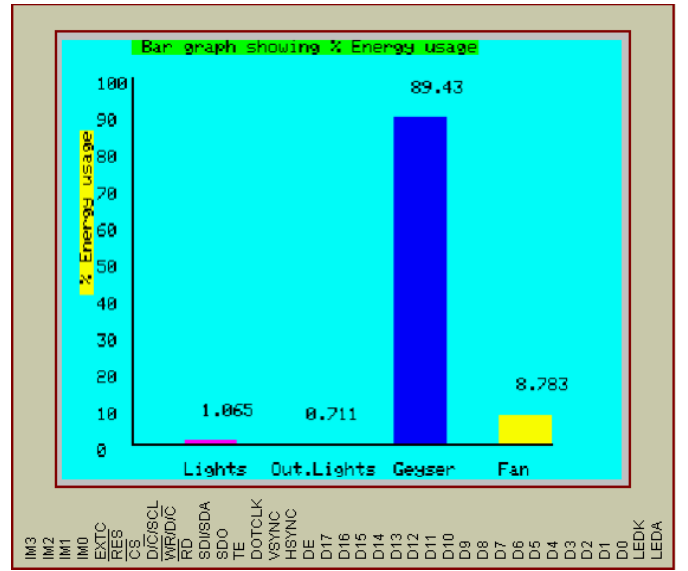

Figure 7. Bar graph showing percentage consumed by connected loads

Table 2. Results for Voltage measurement accuracy

\begin{tabular}{llll}
\multicolumn{4}{c}{ of single-phase meter } \\
\hline Load & Voltage (V) & \\
\hline & Actual & Measured & Error \\
voltage (V) & voltage (V) & $(\%)$ \\
Lights & 12 & 11.99 & 0.083 \\
Outdoor & 12 & 11.99 & 0.083 \\
lights & & & \\
Geyser & 230 & 225.7 & 1.870 \\
Fan & 230 & 229.8 & 0.087 \\
\hline
\end{tabular}

Table 4. Results for power factor accuracy of single-phase meter

\begin{tabular}{llll}
\hline Load & Power factor & & \\
\hline & Actual power & Measured power & Error \\
& factor & factor & $(\%)$ \\
Lights & 1 & 1 & 0 \\
Outdoor & 1 & 1 & 0 \\
lights & & & \\
Geyser & 1 & 1 & 0 \\
Fan & 1 & 0.998 & 0.2 \\
\hline
\end{tabular}

Table 6. Results for energy accuracy of single-phase meter

\begin{tabular}{cccc}
\hline Load & \multicolumn{3}{c}{ Energy $(\mathrm{kWh})$} \\
\hline & Actual & Measured & Error \\
energy $(\mathrm{kWh})$ & energy $(\mathrm{kWh})$ & $(\%)$ \\
Lights & 0.000600 & 0.000597 & 0.5 \\
Geyser & 0.051667 & 0.050295 & 2.66 \\
Fan & 0.005000 & 0.005006 & 0.12 \\
\hline
\end{tabular}

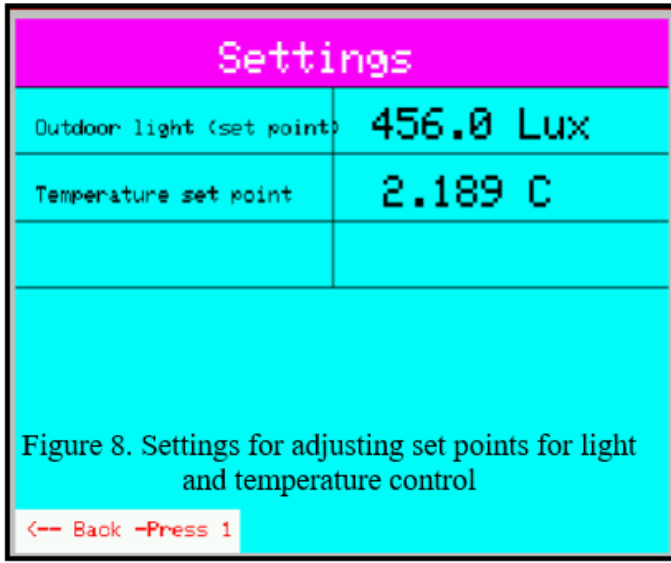

Figure 8. Settings for adjusting set points for light and temperature control

Table 3. Results for Current measurement accuracy of single-phase meter

\begin{tabular}{llll}
\hline Load & Current (A) & & \\
\hline & Actual & Measured & Error \\
current (A) & $\begin{array}{l}\text { current (A) } \\
(\%)\end{array}$ \\
Lights & 3 & 3.018 & 0.6 \\
$\begin{array}{l}\text { Outdoor } \\
\text { lights }\end{array}$ & 2 & 2.016 & 0.8 \\
Geyser & 13.48 & 13.49 & 0.074 \\
Fan & 1.304 & 1.321 & 1.304 \\
\hline
\end{tabular}

Table 5. Results for power accuracy of single-phase meter

\begin{tabular}{llll}
\hline Load & Power (W) & & \\
\hline & Actual power & Measured power & Error \\
& $(\mathrm{W})$ & $(\mathrm{W})$ & 0.528 \\
Lights & 36 & 36.19 & 0.750 \\
$\begin{array}{l}\text { Outdoor } \\
\text { lights }\end{array}$ & 24 & 24.18 & \\
Geyser & 3100 & 3047.10 & 1.706 \\
Fan & 300 & 303.201 & 1.607 \\
\hline
\end{tabular}

Table 7. Results for power accuracy of three- phase meter

\begin{tabular}{cccc}
\hline $\begin{array}{c}\text { Phase under } \\
\text { loading }\end{array}$ & \multicolumn{3}{c}{ Power (W) } \\
& $\begin{array}{c}\text { Actual } \\
\text { power }(\mathrm{W})\end{array}$ & $\begin{array}{c}\text { Measured } \\
\text { power }(\mathrm{W})\end{array}$ & $\begin{array}{c}\text { Error } \\
(\%)\end{array}$ \\
Red Phase & 3910 & 3961.56 & 1.319 \\
Yellow Phase & 3910 & 3878.58 & 0.804 \\
Blue Phase & 3910 & 3878.58 & 0.804 \\
\hline
\end{tabular}

\subsection{Three phase load power management analysis}

The TFT display after one minute of simulation for the above three phase induction motor is shown Figure 9. The tested results are shown in Table 7 and Table 8 . The results shows a close proximity over a simulation period of one minute. The actual energy consumed is compared against the and the measured energy. The difference between the two quantities is due to the Arduino Mega system rounding up or rounding down the analogue voltages being read to the nearest integer.

The results can be improved by taking more samples from the ac voltage and current sensor, over smaller intervals so this would increase the accuracy in determining the peak value and therefore improve the accuracy of the rms voltage and current calculations. 


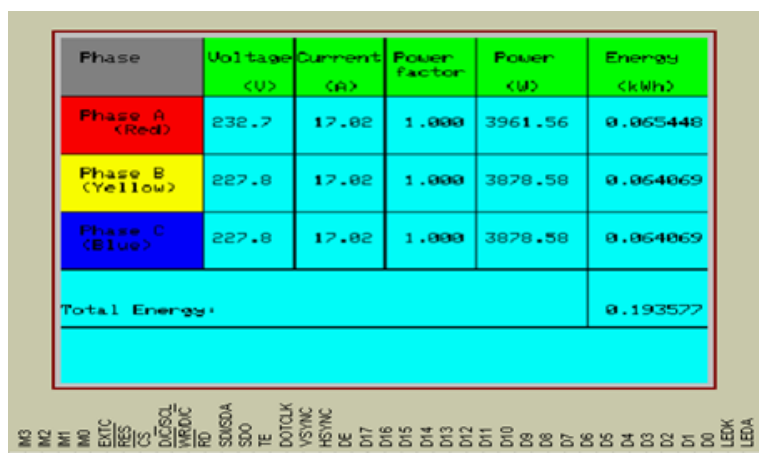

Table 8. Results for energy accuracy of three-phase meter

\begin{tabular}{llll}
\hline Phase under loading & \multicolumn{3}{c}{ Energy $(\mathrm{kWh})$} \\
\hline Red Phase & 0.065167 & 0.065448 & 0.432 \\
Yellow Phase & 0.065167 & 0.064069 & 1.685 \\
Blue Phase & 0.065167 & 0.064069 & 1.685 \\
\hline
\end{tabular}

Figure 9. Screen display on TFT of simulation of real time measurement for operating three phase load

\section{CONCLUSION}

The single phase and three phase load analysis and power management system using Proteus Visual Desing was simulated and tested for various load values similar to residential and industrial load parameters. The simulation results represent the ideal case, including the factors such as resistor tolerances and stray inductances were not taken into account. The grid power is usually not accurate at $230 \mathrm{Vrms}$ always due to harmonics and change in loading. The load power management system can change due to consumers connecting and disconnecting loads throughout the day, hence the ac voltage in South Africa can vary from 220-250 V rms. Hence the measured rms voltage won't be close to the ideal value of $230 \mathrm{~V}$ rms.

The load analysis and power management system discussed in this paper meets the objective of smart energy metering and automatic load control with simple technique compared to the methods discussed in Section 1. It also offers a user friendly and cost-effective energy metering solution. The system information provided can be easily understood by the user, as displayed in a table format. By using this information, users can better track their energy usage and contribute towards reducing their respective energy consumptions, which will contribute towards reaching energy saving goals of the country and the world overall. The simulated results prove the effiency of the system in measuring the single phase and three phase current and voltage measurements.

\section{REFERENCES}

[1] J.-P. Genet, "Design a small metering system for small and medium sized buildings," Schneider Electric, France, 2010.

[2] M. Mannak, "Public Finance International," 2015. [Online]. Available: http://www.publicfinanceinternational.org/feature/2015/06/economic-impact-south-africa\%E2\%80\%99s-energy-crisis.

[3] A. Zipperer, et al., "Electric Energy Management in the Smart Home: Perspectives on Enabling Technologies and Consumer Behavior," Proceedings of the IEEE, vol. 101, no. 11, pp. 2397-2408, 2013.

[4] "loadshedding.eskom.co.za," [Online] http://loadshedding.eskom.co.za/loadshedding/description. [Accessed 9 July 2016.

[5] T. A. Edison, "Electric meter," New Jersey Patent 251 545, 27 December 1881.

[6] P. Aswathy and C. Shanthi, "An Automated Energy Metering System," International Journal of Advanced Research in Electrical, Electronics and Instrumentation Engineering, vol. 3, no. 3, pp. 8064-8067, 2014.

[7] S. Svensson, "Power Management techniques for non-sinusoidal condition," Thesis-for the degree of Doctor of Philosophy, 1999.

[8] S. Modi, et al., "Intelligent Energy Management System for Residential buildings based on ZigBee Technology," International Journal of Power System Operation and Energy Management System, vol. 2, no. 1-2, pp. 35-40, 2011.

[9] O. G. Martinsen and S. Grimnes, "Bioimpedance and Bioelectricity Basics," UK Academic Press, p. 213, 2018. "Allegro Microsystems LLC," 2016. [Online]. Available: http://www.allegromicro.com/en/Products/CurrentSensor-ICs/Zero-To-Fifty-Amp-Integrated-Conductor-Sensor-ICs/ACS712.aspx.

[10] I. U. Rahman, "Smart Net Energy Metering System," Journal of Electrical and Electronic Systems, vol. 7, no. 4, pp. 285-289, 2018.

[11] Adeeribigbe Israel Adekitan, et.al. "Data based investigation of the energy metering type, billing and usage of sampled residents of Ota community in Nigeria," Data in Brief, vol. 20, pp. 159-172, 2018.

[12] Amrita Singh, et.al. "IoT based smart energy meter," International Journal of Advance Research and Development, vol. 3, no. 3, pp. 328-331, 2018.

[13] Sandhya Shinde, et.al. "IoT based Smart Energy Meter," International Journal of Trend in Scientific Research and Development (IJTSRD), vol. 1, no. 6, pp. 1150-1153, 2017.

[14] M. Prathik,et al, "Smart Energy Meter Surveillance Using IoT," 2018 International Conference on Power, Energy, Control and Transmission Systems (ICPECTS), Chennai, pp. 186-189, 2018. 
[15] Vedant Parmar, et al., "Hi-Tech Energy Meter with Automatic Load Control, International Journal of Science Technology \& Engineering, vol. 1, no. 11, pp. 59 -62, 2015.

[16] Ashwini Kumari, et al., "Artificial Neural Network-Based Smart Energy Meter Monitoring and Control Using Global System for Mobile Communication Module”, Soft Computing for Problem Solving, vol. 1057, pp.1-8, 2019.

[17] Raheel Muzzammel, et. "Advanced energy management system with the incorporation of novel security features", International Journal of Electrical and Computer Engineering (IJECE), 2020, vol.10. No. 4, pp. 3978-3987.

[18] M. Bragard, et al., "The Balance of Renewable Sources and User Demands in Grids: Power Electronics for Modular Battery Energy Storage Systems," IEEE Transactions on Power Electronics, 2010, Vol. 25, No. 12, pp. 3049-3056

[19] K. Thirugnanam, et al., "Battery integrated solar photovoltaic energy management system for micro-grid," 2015 IEEE Innovative Smart Grid Technologies - Asia (ISGT ASIA), Bangkok, 2015, pp. 1-7

[20] M. A. A. Pedrasa, et al., "Coordinated Scheduling of Residential Distributed Energy Resources to Optimize Smart Home Energy Services," in IEEE Transactions on Smart Grid, vol. 1, no. 2, 2010, pp. 134-143

[21] Rahul Ganesh Sarangle, et al., "GSM Based Power Meter Reading and Control System", International Journal of Advanced Research in Computer Engineering \& Technology, Vol 1, Iss. 4, 2012, pp. 273-279.

[22] L. Karunarathne, et al., "Model based power and energy management system for PEM fuel cell/ Li-Ion battery driven propulsion system," 5th IET International Conference on Power Electronics, Machines and Drives (PEMD 2010), 2010, pp. 1-6

[23] H. Lee, et al., "Operation and Control Strategy of Energy Management System for LVDC Distribution System," 2019 IEEE 4th International Future Energy Electronics Conference (IFEEC), 2019, pp. 1-8

[24] Nabil Mohammad et al., “A Smart Prepaid Energy Metering System to Control Electricity Theft,"International Conference on Power, Energy and Control, 2013, pp. 562-569.

[25] Somefun T.E, et al., "Smart prepaid energy metering system to detect energy theft with facility for real time monitoring", International Journal of Electrical and Computer Engineering, Vol. 9, No. 5, 2019, pp. $4184-4191$

\section{BIOGRAPHIES OF AUTHORS}
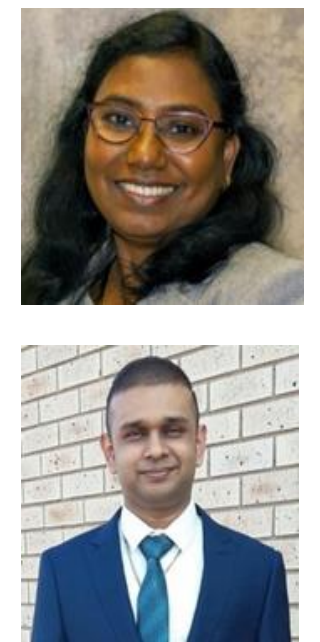

Chitra Venugopal has completed her Bacheolar of Engineering in Electronics and Communication Engineering and Master of Engineering in Power Electronics and Drives from Bharathidasan University, India. She completed her Ph.D in Electrical Engineering from SASTRA University, India. She has authored several research papers published in international journals and conferences. She worked in India, Malaysia, Ethiopia, South Africa, West Indies and currently working at Oregon Institute of Technology, OR, USA. Her research interests includes, power electronics and machine drives, micro-grid and smart grid power systems, renewable energy sources, solar and wind predication system and soft computing techniques.

Thershen Govender graduated from University of KwaZulu-Natal with a Bacheolar degree in Electrical Engineering. He is currently working as an Electrical Engineer at Mercede-Benz, South Africa. During his studies he won second prize in international design competition. His research interests are in programmable logic controllers, power electronics and drives. 